\title{
Offspring birthweight is not associated with paternal insulin resistance
}

\author{
B. Knight • B. M. Shields • A. Hill • R. J. Powell • \\ A. Round • W. Hamilton • A. T. Hattersley
}

Received: 19 April 2006 / Accepted: 20 July 2006 / Published online: 5 September 2006

(C) Springer-Verlag 2006

\begin{abstract}
Aims/hypothesis Low birthweight is associated with insulin resistance and other insulin resistance-related phenotypes: diabetes, hypertension, and vascular disease in later life. The underlying mechanism is unclear. The foetal insulin hypothesis proposes that a single genetic predisposition to beta cell dysfunction/insulin resistance results in both reduced insulin-dependent foetal growth in utero, hence low birthweight, and predisposition to type 2 diabetes. The aim of this study was to test whether, as predicted by the foetal insulin hypothesis, there is an association between measures of paternal insulin resistance and offspring birthweight.
\end{abstract}

B. Knight $\cdot$ B. M. Shields $\cdot$ A. Hill $\cdot$ R. J. Powell

A. T. Hattersley $(\bowtie)$

Diabetes and Vascular Medicine, Peninsula Medical School,

Barrack Road,

Exeter EX2 5DW, UK

e-mail: A.T.Hattersley@ex.ac.uk

B. Knight

Maternity Unit (Heavitree),

Royal Devon and Exeter NHS Foundation Trust,

Exeter, UK

\section{R. J. Powell}

Research and Development Support Unit,

Exeter, UK

\author{
A. Round \\ East Devon Primary Care Trust, \\ Clyst Honiton, \\ Exeter, UK \\ W. Hamilton \\ Barnfield Hill Research Practice, \\ Exeter, UK
}

Subjects and Methods The Exeter Family Study of Childhood Health (EFSOCH) is a community-based study within central Exeter (UK), established to test the foetal insulin hypothesis prospectively. Associations were tested between offspring birthweight and paternal insulin resistance, calculated by homeostasis model assessment analysis in 986 families using data relating to singleton, non-diabetic, UK white pregnancies. Ethics approval was given by the North and East Devon local ethics committee.

Results Offspring birthweight was not significantly correlated with $\log$ paternal insulin resistance $(r=0, p=0.91)$, $\log$ HDL cholesterol concentration $(r=-0.02, p=0.47)$ or $\log$ triglyceride concentration $(r=0, p=0.99)$ when corrected for paternal BMI and common confounders. Multiple linear regression analysis confirmed that paternal insulin resistance was not an independent predictor of offspring birthweight.

Conclusions/interpretation Results from a young, adult, non-diabetic population do not support the foetal insulin hypothesis as an explanation for the association of low birthweight with insulin resistance.

Keywords Birthweight · Insulin resistance - Offspring · Paternal

\section{Abbreviations \\ HOMA homeostasis model assessment}

\section{Introduction}

Low birthweight is associated with insulin resistance and related conditions, including type 2 diabetes, but the underlying mechanism is unclear [1]. The thrifty phenotype 
hypothesis proposes that foetal malnutrition in utero results in reduced foetal growth and programming of the foetus to be insulin-resistant postnatally [2]. In contrast, the foetal insulin hypothesis proposes that low birthweight and type 2 diabetes are two phenotypes of a genetic predisposition to insulin resistance and/or beta cell dysfunction that reduces insulin-dependent foetal growth in utero as well as predisposing to type 2 diabetes [3].

We proposed that, if insulin resistance is in part genetically determined, a test of the foetal insulin hypothesis would be that offspring of insulin-resistant fathers, who will inherit $50 \%$ of paternal genes, should have reduced insulin-mediated growth in utero, and hence lower birthweight [3]. Therefore, the primary analysis in this study was to test whether paternal insulin resistance is inversely associated with offspring birthweight.

\section{Subjects and methods}

The Exeter Family Study of Childhood Health (EFSOCH) was established to test the foetal insulin hypothesis prospectively. Details of the study, recruitment, protocol and planned analysis have been described previously [4]. In brief, we recruited both parents from 1,017 singleton, nondiabetic pregnancies from central Exeter, UK. At 28 weeks of gestation we measured parental height, weight, BMI and waist/hip ratio, and measures of paternal and maternal insulin resistance (including homeostasis model assessment [HOMA] [5], fasting plasma:glucose ratio, and insulin, HDL cholesterol and triglyceride concentrations). Offspring weight, length, head circumference and skin-fold thickness were measured at birth. DNA from the mother, father and baby were analysed to confirm family relationships.

Associations were examined between measures of paternal insulin resistance and offspring birthweight, corrected for sex and gestation, using correlation and regression analysis. The models were adjusted for potential maternal confounders, including prepregnant BMI, smoking, fasting glucose, insulin resistance and parental height. Variable distributions were assessed for normality and were log-transformed when necessary.

\section{Results}

Characteristics of study group

Of the original 1,017 families recruited, 27 families were excluded before birth and a further four families were excluded after birth [4]. The characteristics of the parents and offspring of the remaining 986 families at 28 weeks of gestation are given in Table 1.
Paternal insulin resistance and offspring birthweight

There was no significant correlation between paternal $\log$ insulin resistance and offspring birthweight corrected for known confounding factors and paternal BMI $(r=-0.01, p=0.74)$ (Table 2). Traits associated with paternal insulin resistance were not correlated with corrected birthweight (log HDL, $r=-0.02, p=0.55$; log triglyceride concentration, $r=0, p=0.95$ ). Excluding offspring born before 37 weeks of gestation $(n=943)$ made no difference to the results.

Paternal insulin resistance and offspring birth parameters associated with insulin resistance

There were no significant correlations between paternal log insulin resistance and other measures of offspring growth: length $(r=0.02, p=0.58)$; head circumference $(r=0.01$,

Table 1 Baseline characteristics of 986 families (offspring and their parents)

\begin{tabular}{|c|c|c|}
\hline & $\begin{array}{l}\text { Mean or } \\
\text { geometric mean }\end{array}$ & SD range \\
\hline \multicolumn{3}{|l|}{ Mothers } \\
\hline Age (years) & 30.4 & $25.2-35.6$ \\
\hline Height $(\mathrm{cm})$ & 165.0 & $158.7-171.3$ \\
\hline Prepregnant weight $(\mathrm{kg})$ & $63.1^{\mathrm{a}}$ & $52.5-173.8$ \\
\hline Prepregnant BMI $\left(\mathrm{kg} / \mathrm{m}^{2}\right)$ & $23.4^{\mathrm{a}}$ & $19.9-27.5$ \\
\hline Pregnant weight $(\mathrm{kg})$ & $75.8^{\mathrm{a}}$ & $64.6-89.1$ \\
\hline Fasting plasma glucose $(\mathrm{mmol} / \mathrm{l})$ & 4.3 & $3.9-4.7$ \\
\hline Fasting plasma insulin $(\mathrm{pmol} / \mathrm{l})$ & $60.3^{\mathrm{a}}$ & $20.9-173.8$ \\
\hline \multicolumn{3}{|l|}{ Fathers } \\
\hline Age & 32.9 & $26.9-38.9$ \\
\hline Height $(\mathrm{cm})$ & 178.0 & $171.4-184.6$ \\
\hline Weight (kg) & $83.2^{\mathrm{a}}$ & $70.8-97.7$ \\
\hline BMI $\left(\mathrm{kg} / \mathrm{m}^{2}\right)$ & $26.3^{\mathrm{a}}$ & $22.9-30.2$ \\
\hline Waist/hip ratio & 0.9 & $0.8-1.0$ \\
\hline Plasma HDL cholesterol (mmol/l) & $1.3^{\mathrm{a}}$ & $1.0-1.7$ \\
\hline Triglycerides $(\mathrm{mmol} / \mathrm{l})$ & $1.3^{\mathrm{a}}$ & $0.77-2.24$ \\
\hline Fasting plasma glucose $(\mathrm{mmol} / \mathrm{l})$ & 4.7 & $4.3-5.1$ \\
\hline Fasting plasma insulin (pmol/1) & $54.9^{\mathrm{a}}$ & $30.9-97.7$ \\
\hline HOMA-IS & $85.1^{\mathrm{a}}$ & $49.0-147.9$ \\
\hline \multicolumn{3}{|l|}{ Babies (491 males) } \\
\hline Gestation (weeks) & $40.1^{\mathrm{b}}$ & $39.0-41.0$ \\
\hline Length $(\mathrm{cm})$ & 50.2 & $48.1-52.3$ \\
\hline Birthweight (g) & 3462 & $2947-3977$ \\
\hline Ponderal index $\left(\mathrm{kg} / \mathrm{m}^{3}\right)$ & 27.6 & $25.0-30.2$ \\
\hline
\end{tabular}

Parental fasting blood and parental anthropometric measures were determined at 28 weeks of gestation; offspring measures were determined within $24 \mathrm{~h}$ of birth

HOMA-IS homeostasis model assessment of insulin sensitivity

${ }^{a}$ Geometric mean and SD range; ${ }^{b}$ median and interquartile range; other data are mean and SD range 
Table 2 Relationship of offspring birthweight with paternal insulin resistance: correlations of paternal insulin resistance, and traits related to paternal insulin resistance, with offspring birthweight and offspring birthweight corrected for common confounders (gestational age, sex, maternal parity and socio-economic status $[\mathrm{SES}]$ ) and paternal BMI

\begin{tabular}{|c|c|c|c|c|c|c|}
\hline & \multicolumn{2}{|c|}{ Birthweight } & \multicolumn{2}{|c|}{$\begin{array}{l}\text { Birthweight corrected for sex, } \\
\text { gestational age, parity and SES }\end{array}$} & \multicolumn{2}{|c|}{$\begin{array}{l}\text { Birthweight corrected for sex, gestational } \\
\text { age, parity, SES and paternal BMI }\end{array}$} \\
\hline & $r$ & $p$ & $r$ & $p$ & $r$ & $p$ \\
\hline \multicolumn{7}{|l|}{ Full data set $(n=986)$} \\
\hline Log paternal insulin resistance & 0.02 & 0.62 & 0.01 & 0.79 & -0.01 & 0.74 \\
\hline Log paternal HDL cholesterol concentration & -0.05 & 0.16 & -0.03 & 0.34 & -0.02 & 0.55 \\
\hline Log paternal triglyceride concentration & 0 & 0.91 & 0.02 & 0.61 & 0 & 0.95 \\
\hline \multicolumn{7}{|l|}{ Term only data set $(n=943)$} \\
\hline Log paternal insulin resistance & 0.01 & 0.75 & 0.01 & 0.73 & 0 & 0.91 \\
\hline Log paternal HDL cholesterol concentration & -0.04 & 0.28 & -0.03 & 0.32 & -0.02 & 0.47 \\
\hline Log paternal triglyceride concentration & -0.01 & 0.80 & 0.01 & 0.69 & 0 & 0.99 \\
\hline
\end{tabular}

$p=0.80)$; sum of skin-fold thicknesses $(r=-0.00, p=0.99)$; ponderal index $(r=-0.04, p=0.20)$.

Multivariate analysis

Multiple linear regression analysis was undertaken to assess any independent relationship between parental insulin resistance and offspring birthweight when adjusting for potential confounders (Table 3). There was no relationship between parental insulin resistance and offspring birthweight. In our model, the strongest predictors of offspring birthweight were gestation, foetal sex, maternal parity, maternal smoking, maternal fasting plasma glucose, maternal prepregnancy BMI and parental heights.

\section{Discussion}

This prospective study did not confirm the prediction of the foetal insulin hypothesis, which proposes that offspring birthweight is inversely related to paternal insulin resistance. This is in contrast to a UK study of 2,788 men aged 60-78 years, which found a weak inverse relationship between paternal insulin resistance and offspring birthweight [6], and four studies that have shown that fathers with type 2 diabetes have offspring with reduced birthweight [6-9]. It appears that birthweight has a weaker inverse association with paternal insulin resistance than with paternal diabetes [6], so our study may have been underpowered. However, our study had sufficient power to detect a difference as small as $50 \mathrm{~g}$. Our subjects were approximately half the age of the subjects in the study by Wannamethee and colleagues [6], which might be part of the explanation for the different results.

Table 3 Relationship of offspring birthweight with paternal insulin resistance: multiple linear regression analysis with offspring birthweight ( $\mathrm{g}$ ) as dependent variable $(n=943)$

\begin{tabular}{lllll}
\hline & $b$ & Lower 95\% confidence limit & Upper 95\% confidence limit & $t$ \\
\hline Sex (male) & 125 & 71 & 178 & 4.6 \\
Gestation (weeks) & 167 & 145 & 190 & $<0.001$ \\
Primiparous & -182 & -236 & -128 & $<0.001$ \\
Maternal smoking & -238 & -324 & -153 & $<0.001$ \\
Maternal fasting glucose & 218 & 137 & 299 & $<0.601$ \\
Maternal prepregnant BMI & 15 & 8 & 22 & -6.6 \\
Maternal height & 15 & 10 & 19 & 5.3 \\
Paternal height & 7 & 3 & 11 & 4.0 .1 \\
Socio-economic status & 6 & -2 & 15 & $<0.001$ \\
Paternal BMI & 4 & -4 & 12 & $<0.001$ \\
Paternal log insulin resistance & -48 & -177 & 81 & $<.5$ \\
Maternal log insulin resistance & 44 & -133 & 201 & 0.001 \\
\hline
\end{tabular}

$b$ Regression coefficient; $t$ t-statistic defined as $b /$ standard error 
It is unlikely that the failure of our study to see any association was due to methodological difficulties. Our study benefited from the availability of a large number of prospectively collected parental and offspring data which had been obtained using strict quality control measures. The availability of considerable information on the mothers allowed all known confounders to be corrected for in the analysis.

The foetal insulin hypothesis assumes that foetal insulin resistance would result in reduced insulin-mediated growth in utero. However, if there was foetal compensation for increased foetal insulin resistance, this could result in foetal hyperinsulinaemia, and hence foetal growth would be relatively maintained despite a reduced response to insulin by the foetal tissues. This has been demonstrated in Indian babies, who are smaller and more insulin-resistant compared with European white babies, yet show increased cord insulin values [10]. Further support for foetal compensation comes from the inverse association between paternal insulin resistance and cord insulin concentrations we have seen in this cohort [11].

The foetal insulin hypothesis is based on the inheritance of genes that alter not only insulin resistance but also insulin secretion. For pragmatic reasons, this study was designed to examine paternal insulin resistance using HOMA from fasting plasma glucose and insulin concentrations. We were unable to measure beta cell function effectively, as this would require measuring a stimulated response such as insulin secretion in response to an oral glucose load, which would have required considerable additional resources. It is possible that the clearly reduced birthweight of offspring of fathers with type 2 diabetes [6-9] reflects the inheritance of genetic susceptibility to beta cell dysfunction. One approach that could be used to study this in the future would be to use the DNA that is available from the families in our study and look at the impact on birthweight of polymorphisms that predispose to diabetes by reducing beta cell dysfunction.

In conclusion, we have found no relationship between offspring birthweight and paternal insulin resistance in a cohort of young, white, singleton, non-diabetic pregnancies. This result does not support the foetal insulin hypothesis as the explanation of the inverse association between birthweight and insulin resistance.

Acknowledgements This study was funded by South West NHS Research and Development, Exeter NHS Research and Development and the Darlington Trust. A.T. Hattersley is a Wellcome Trust Research Leave fellow. B. Knight holds an NHS Research and Development studentship. W. Hamilton holds an NHS fellowship.

\section{References}

1. Levy-Marchal C, Jaquet D (2004) Long-term metabolic consequences of being born small for gestational age. Pediatr Diabetes $5: 147-153$

2. Barker DJ (1995) Intrauterine programming of adult disease. Mol Med Today 1:418-423

3. Hattersley AT, Tooke JE (1999) The fetal insulin hypothesis: an alternative explanation of the association of low birthweight with diabetes and vascular disease. Lancet 353:1789-1792

4. Knight B, Shields BM, Hattersley AT (2006) The Exeter Family Study of Childhood Health (EFSOCH): study protocol and methodology. Paediatr Perinat Epidemiol 20:172-179

5. Levy JC, Matthews DR, Hermans MP (1998) Correct homeostasis model assessment (HOMA) evaluation uses the computer program. Diabetes Care 21:2191-2192

6. Wannamethee SG, Lawlor DA, Whincup PH, Walker M, Ebrahim S, Davey-Smith G (2004) Birthweight of offspring and paternal insulin resistance and paternal diabetes in late adulthood: cross sectional survey. Diabetologia 47:12-18

7. Davey Smith G, Sterne JA, Tynelius P, Rasmussen F (2004) Birth characteristics of offspring and parental diabetes: evidence for the fetal insulin hypothesis. J Epidemiol Commun Health 58:126-128

8. Hypponen E, Smith GD, Power C (2003) Parental diabetes and birth weight of offspring: intergenerational cohort study. BMJ 326:19-20

9. Lindsay RS, Dabelea D, Roumain J, Hanson RL, Bennett PH, Knowler WC (2000) Type 2 diabetes and low birth weight. Diabetes 49:445-449

10. Yajnik CS, Lubree HG, Rege SS et al (2002) Adiposity and hyperinsulinemia in Indians are present at birth. J Clin Endocrinol Metab 87:5575-5580

11. Shields BM, Knight B, Turner M et al (2006) Paternal insulin resistance and its association with umbilical cord insulin concentrations. Diabetologia DOI 10.1007/s00125-006-0282-8 